\title{
PENERAPAN ALGORITMA ID3 UNTUK MENYELEKSI PEGAWAI KONTRAK DI KANTOR PENGADILAN KOTA LANGSA
}

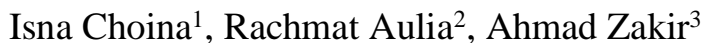

\author{
${ }^{1,2}$ Program Studi Teknik Informatika Universitas Teknik Harapan Medan \\ ${ }^{3}$ Program Studi Sistem Informasi Universitas Harapan Medan \\ JL. HM.Joni.No.70 Medan \\ 1'choina_isna@yahoo.com, ${ }^{2}$ jackm4t@gmail.com, ${ }^{3}$ suratzakir@gmail.com
}

\begin{abstract}
Abstrak - Sistem kerja kontrak terjadi pada semua jenis industri dengan waktu yang tidak ditentukan. Termasuk di kantor pengadilan Kota Langsa dimana jumlah karyawan kontrak sudah harus di kurangi. Maka perlu dilakukan adanya penyeleksian karyawan kontrak berprestasi agar dapat di pertahankan di kantor pengadilan Kota Langsa, dengan melihat ketentuan dan syarat yang telah di tetapkan. Namun penentuannya pada saat ini masih kurang tepat dan butuh banyak waktu, di karenakan penulisan dan perhitungan hasilnya masih dilakukan secara bertahap. Sehingga adanya kemungkinan kesalahan dalam memutuskan hasil akhirnya. Berdasarkan permasalahan yang telah di jelaskan tersebut maka, perlu adanya solusi pemecahan masalah. Penelitian ini dapat membantu perusahaan dalam memilih karyawan berprestasi dengan tepat menggunakan pemrograman Visual basic 2010 dan menggunakan algoritma ID3 (Iterative dichotomiser three) yang menghasilkan pohon keputusan.
\end{abstract}

Kata kunci- Karyawan kontrak, Algoritma ID3, Pohon Keputusan, Visual Basic 2010.

Abstract - Contract work systems occur in all types of industries with an unspecified time. Regarding the municipal court office where the number of employees must have been approved. Then it is necessary to select outstanding contract employees so that they can be maintained in the langsa city court office, taking into account the terms and conditions that have been set. But his decision at this time was still not right and needed a lot of time, in accordance with the provisions and calculations were carried out in stages. Possible Attendance. Based on the considerations that have been explained then, there needs to be a solution to solve the problem. This research can assist companies in selecting high-performing employees by using Visual Basic 2010 programming and using the ID3 algorithm (three-dichotomous repetition) which produces a decision tree.

Keyword — Contract employee, ID3 Algorithm, Decision tree, Visual Basic 2010.

\section{PENDAHULUAN}

Pegawai kontrak adalah karyawan yang diperbantukan untuk menyelesaikan pekerjaan rutin perusahaan, dan tidak ada jaminan kelangsungan masa kerjanya. Sistem kerja kontrak terjadi pada semua jenis industri dengan waktu yang tidak ditentukan. Kewajiban kerja karyawan kontrak terkadang hampir sama atau bahkan lebih berat dari pada pegawai tetap. Dalam kelangsungan masa kerja pegawai kontrak ditentukan oleh prestasi kerjanya. Semakin bagus prestasi kerjanya maka, pegawai kontrak akan dipertahankan oleh perusahaan, namun jika prestasi kerjanya tidak ada peningkatan maka perusahaan akan memberhentikan pegawai tersebut[1].

Penyeleksian karyawan kontrak berprestasi agar dapat di pertahankan di kantor pengadilan kota langsa, dengan melihat ketentuan dan syarat yang telah di tetapkan. Namun penentuannya pada saat ini masih kurang tepat dan butuh banyak waktu, di karenakan penulisan dan perhitungan hasilnya masih dilakukan secara bertahap. Sehingga adanya kemungkinan kesalahan dalam memutuskan hasil akhirnya.

Untuk melakukan penyeleksian perangkingan pegawai kontrak harus memenuhi beberapa kriteria atau syarat dasar pengambilan keputusan antara lain kerapian, kedisiplinan, kehadiran, kemampuan. Jika pegawai kontrak tersebut telah memenuhi nilai kriteria-kriteria yang sudah ditentukan maka pegawai kontrak tersebut termasuk dalam kategori pegawai kontrak berprestasi sehingga dapat terus di pertahankan.

Berdasarkan permasalahan yang telah di jelaskan tersebut maka, perlu adanya solusi pemecahan masalah. Penelitian ini dapat membantu perusahaan dalam memilih karyawan berprestasi dengan tepat menggunakan pemrograman Visual basic 2010 dan menggunakan algoritma ID3(Iterative dichotomiser three) untuk menghitung hasil dalam penentuan karyawan kontrak berprestasi.

Dalam skripsi ini akan dibahas pemakaian pohon keputusan (Decision tree). untuk Seleksi Perangkingan Pegawai kontrak menggunakan 
Algoritma ID3(Iterative dichotomiser three) di kantor Pengadilan Kota Langsa.

\section{LANDASAN TEORI}

\section{Page | 48}

\section{A. Data Mining}

Data Mining merupakan penambangan atau penemuan informasi baru dengan mencari pola atau aturan tertentu dari sejumlah data dalam jumlah besar yang diharapkan dapat mengatasi kondisi tersebut. Data Mining sendiri memiliki beberapa teknik salah satunya klasifikasi. Teknik klasifikasi terdiri beberapa metode, dan decision tree adalah bagian dari metode klasifikasi. Kemudian metode decision tree memiliki algoritma, algoritma ID3 adalah salah satu dari algoritma yang memiliki decision tree. Data mining sebuah proses untuk mendapatkan informasi yang berguna dari gudang basis data yang besar. Data mining juga dapat diartikan sebagai pengekstrakan informasi baru yang diambil dari bongkahan data besar yang membantu dalam pengambilan keputusan Istilah data mining kadang disebut juga knowledge discovery [2].

\section{B. Database}

Data base adalah kumpulan dari data yang saling terhubung (interrelated data) yang disimpan secara bersama-sama pada suatu media, tanpa ada kerusakan atau kerangkapan data, sehingga proses penambahan, pengambilan dan modifikasi data dapat dilakukan dengan mudah dan terkontrol [3].

\section{Pohon Keputusan}

Pohon keputusan adalah salah satu metode klasifikasi yang paling populer karena mudah di interperensi manusia. Pohon keputusan adalah model prediksi menggunakan struktur pohon atau struktur berhirarki. Konsep dari pohon keputusan adalah mengubah data menjadi pohon keputusan dan aturanaturan keputusan. Data dalam pohon keputusan biasanya dinyatakan dalam bentuk tabel dengan atribut dan record. Atribut menyatakan suatu parameter yang dibuat sebagai kriteria dalam pembentukan tree[2].

\section{Algoritma ID3(Decision tree learning)}

ID3 atau yang dikenal dengan decision tree learning merupakan metode untuk memperkirakan nilai-diskrit dari suatu fungsi yang diwakili oleh pohon keputusan dimana pohon keputusan tersebut menghasilkan rule IF-Then sehingga menjadi mudah untuk dipahami [4].

Tahapan dari proses algoritma ID3 yaitu sebagai berikut:

1) Menyiapkan data training

2) Hitung nilai Entropy dengan rumus 2.1:

Entropy $(\mathrm{S})=\sum_{i}^{c}-p_{i} \log 2 p_{i}$

Entropy $(\mathrm{S})=\left(-p_{+} \log 2 p_{+}\right)-\left(p_{-} \log 2 p_{-}\right)$

Dimana:

$\mathrm{C}=$ merupakan nilai yang ada pada atribut target yaitu positif dan negatif. Jumlah sampel dari masing masing nilai c yang ada disimbolkan dengan pi. Setelah memperoleh semua nilai entropy, digunakan Information Gain untuk menentukan tingkat efektifitas dari semua atribut. Sehingga bisa ditentukan atribut mana yang memberikan prediksi terbaik yang dilihat dari besarnya information gain atribut tersebut.

3) Setelah mendapatkan nilai entropy akan mencari information gain dari setiap atribut untuk mendapatkan nilai information gain yang paling tinggi.

4) Rumus 2.2 dari Information Gain yaitu :

Gain $(\mathrm{S}, \mathrm{A}) \quad=\quad$ Entropy $(\mathrm{S}) \quad$

$\sum v E$ nilai $(A) \frac{[s v]}{[s]}$ Entropy $(S V)$

$\mathrm{A}=$ salah satu atribut dalam $\mathrm{S}$;

$\mathrm{v}=$ nilai yang mungkin untuk atribut $\mathrm{A}$;

Values $(\mathrm{A})=$ himpunan nilai yang mungkin untuk atribut $\mathrm{A}$;

$|\mathrm{Sv}|=$ jumlah sampel bernilai v;

$|\mathrm{S}|=$ jumlah seluruh sampel;

Entropy $(\mathrm{Sv})=$ Entropy tiap sampel bernilai v .

5) Nilai Information gain yang tertinggi akan terbentuk menjadi simpul yang pertama dan akan menempati paling atas.

6) Proses perhitungan information gain diulangi sampai semua data yang termasuk dalam kelas yang sama..

7) Sehingga akan terbentuk pohon keputusan.

8) Maka akan terbentuk rule-rule [5]

\section{E. Klasifikasi}

Klasifikasi data mining adalah penempatan objek-objek ke salah satu dari beberapa kategori yang telah ditetapkan sebelumnya. Klasifikasi banyak digunakan untuk memprediksi kelas pada suatu label tertentu, yaitu dengan mengklasifikasi data (membangun model) berdasarkan training set dan nilainilai (label kelas) dalam mengklasifikasikan atribut tertentu dan menggunakannya dalam mengklasifikasikan data yang baru. [6]

\section{HASIL DAN PEMBAHASAN}

Pewai kontrak yang bekerja di kantor pengadilan akan dikontrak selama 1 tahun sekali dan setiap tahun akan di lakukan penyeleksian pegawai kontrak berprestasi. Berikut ini merupakan atribut dari data set yang terdiri dari keahlian, kerapian, kehadiran, prilaku dan keterangan. Adapun fitur nomor dan nama adalah kode untuk menentukan variabel yang diambil agar tidak terjadinya kesamaan atau perulangan yang tidak di perlukan dalam proses data mining. Untuk menentukan prediksi seleksi perangkingan pegawai kontrak berprestasi yang layak dipertahankan dengan atribut keterangan layak atau tidak layak. Nilai atribut menggunakan tipe kategorikal, rinciannya sebagai berikut:

1) Keahlian $=\{$ ahli, kurang $\}$

2) Kerapian $=\{$ ya, tidak $\}$

3) Kehadiran $=\{$ selalu, jarang $\}$

4) Perilaku $=\{$ baik, Kurang $\}$

Untuk menentukan penilaian dari masing-masing nilai atribut terdapat beberapa ketentuan yaitu:

1) Seseorang dikatakan rapi bila memenuhi beberapa kriteria yaitu:

a) Pakaian tidak kusut 
$\begin{array}{ll}\text { Page } \mid 49 & \text { c) Sepatu bersih } \\ & \text { d) Rambut tidak berantakan dan tertata }\end{array}$

2) Seseorang dikatakan selalu hadir bila dalam sebulan karyawan absen paling banyak 3 kali bila melewati batas yang ditentukan akan di kenakan SP (surat peringatan). Jumlah Sp yang paling bayak di terima dalam setahun adalah 3 kali.

3) Seseorang dikatakan ahli apa bila karyawan tersebut mampu menguasai semua pekerjaan dalam bidang yang di tempatkan.

4) Seseorang karyawan yang dikatan mempunyai perilaku baik apa bila memenuhi beberapa ketentuan yaitu:

a) Tidak membantah atasan

b) Melakukan semua perintah dengan segera

Diluar dari ketentuan yang telah di jelaskan diatas maka dikatan seseorang memiliki nilai atribut "Kurang" dan "Jarang". Setiap fitur dalam atribut memiliki bobot masing-masing untuk mempermudah penilaian layak atau tidak layak, dengan nilai keseluruhan setiap fitur $100 \%$.

TABEL I

\begin{tabular}{|c|c|c|}
\hline \multirow{2}{*}{ Keahlian } & Ahli & 21 \\
\hline & Kurang & 16 \\
\hline \multirow{2}{*}{ Kerapian } & $\mathrm{Ya}$ & 10 \\
\hline & Kurang & 7 \\
\hline \multirow{2}{*}{ Kehadiran } & Selalu & 15 \\
\hline & Jarang & 10 \\
\hline \multirow{2}{*}{ Perilaku } & Baik & 13 \\
\hline & Kurang & 8 \\
\hline Total & \multicolumn{2}{|c|}{100} \\
\hline
\end{tabular}

Bila nilai Keseluruhan setiap fitur $=>54 \%$ maka dianggap layak. Namun bila nilai keseluruhan fitur < 54\% maka dianggap tidak layak.

Data set pada tabel 2 dilakukan untuk melakukan prediksi seleksi perangkingan pegawai kontrak berprestasi agar terus di pertahankan. Dengan cara menjawab layak atau tidak layak. Dengan menggunakan fitur : Nama, Keahlian,Kerapian, Kehadiran, Perilaku.

TABEL II

SET PEGAWAI KONTRAK

\begin{tabular}{|c|c|c|c|c|c|c|}
\hline No & Nama & $\begin{array}{c}\text { Keahlia } \\
\mathrm{n}\end{array}$ & $\begin{array}{c}\text { Kerapia } \\
\mathrm{n}\end{array}$ & $\begin{array}{c}\text { Kehadira } \\
\mathrm{n}\end{array}$ & $\begin{array}{c}\text { Perilak } \\
\mathrm{u}\end{array}$ & $\begin{array}{c}\text { Keteranga } \\
\mathrm{n}\end{array}$ \\
\hline 1 & Izam Rizki & Ahli & Kurang & Selalu & Baik & Layak \\
\hline 2 & Masuhendra & Ahli & Ya & Selalu & Kurang & Layak \\
\hline 3 & Nursila & Kurang & Kurang & Selalu & Baik & $\begin{array}{c}\text { Tidak } \\
\text { Layak }\end{array}$ \\
\hline 4 & Azizah & Ahli & Ya & Jarang & Baik & Layak \\
\hline 5 & $\begin{array}{c}\text { Aulia } \\
\text { Rachman }\end{array}$ & Kurang & Kurang & Selalu & Baik & $\begin{array}{c}\text { Tidak } \\
\text { Layak }\end{array}$ \\
\hline 6 & $\begin{array}{c}\text { Citra } \\
\text { Pelangi }\end{array}$ & Ahli & Ya & Selalu & Baik & Layak \\
\hline 7 & $\begin{array}{c}\text { Aditya } \\
\text { Permana }\end{array}$ & Ahli & Ya & Selalu & Kurang & Layak \\
\hline 8 & $\begin{array}{c}\text { Ananda } \\
\text { Putra }\end{array}$ & Ahli & Kurang & Jarang & Baik & $\begin{array}{c}\text { Tidak } \\
\text { Layak }\end{array}$ \\
\hline 9 & Sawaluddin & Ahli & Kurang & Selalu & Kurang & $\begin{array}{c}\text { Tidak } \\
\text { Layak }\end{array}$ \\
\hline
\end{tabular}

\begin{tabular}{|c|c|c|c|c|c|c|}
\hline 10 & $\begin{array}{l}\text { M.Permata } \\
\text { Sakti }\end{array}$ & Ahli & Ya & Selalu & Baik & Layak \\
\hline 11 & $\begin{array}{c}\text { Fuji } \\
\text { Amalubis }\end{array}$ & Kurang & Ya & Jarang & Kurang & $\begin{array}{l}\text { Tidak } \\
\text { Layak }\end{array}$ \\
\hline 12 & $\begin{array}{c}\text { Kusuma } \\
\text { Devi }\end{array}$ & Kurang & Kurang & Selalu & Baik & $\begin{array}{l}\text { Tidak } \\
\text { Layak }\end{array}$ \\
\hline 13 & $\begin{array}{c}\text { Amalia } \\
\text { Safitri }\end{array}$ & Kurang & $\mathrm{Ya}$ & Selalu & Kurang & $\begin{array}{l}\text { Tidak } \\
\text { Layak }\end{array}$ \\
\hline 14 & $\begin{array}{l}\text { Ahmad } \\
\text { Alwani }\end{array}$ & Ahli & $\mathrm{Ya}$ & Jarang & Baik & Layak \\
\hline 15 & Ali Akbar & Ahli & Kurang & Selalu & Baik & Layak \\
\hline 16 & Abdul Khali & Ahli & $\mathrm{Ya}$ & Selalu & Baik & Layak \\
\hline 17 & $\begin{array}{c}\text { Husnani } \\
\text { Zuhra } \\
\end{array}$ & Kurang & $\mathrm{Ya}$ & Selalu & Kurang & $\begin{array}{l}\text { Tidak } \\
\text { Layak }\end{array}$ \\
\hline 18 & Dyan Febri & Kurang & Kurang & Selalu & Baik & $\begin{array}{l}\text { Tidak } \\
\text { Layak }\end{array}$ \\
\hline 19 & $\begin{array}{l}\text { Dyana } \\
\text { Jafani }\end{array}$ & Ahli & Ya & Selalu & Baik & Layak \\
\hline 20 & $\begin{array}{c}\text { Ryna } \\
\text { Nurhaina }\end{array}$ & Ahli & Kurang & Selalu & Baik & Layak \\
\hline 21 & $\begin{array}{l}\text { Murni } \\
\text { Rofika }\end{array}$ & Kurang & Ya & $\begin{array}{c}\text { Jarang } \\
\text { Hadir }\end{array}$ & Baik & $\begin{array}{l}\text { Tidak } \\
\text { Layak }\end{array}$ \\
\hline 22 & $\begin{array}{c}\text { Balqis } \\
\text { Amalia Sari }\end{array}$ & Kurang & Ya & Selalu & Baik & Layak \\
\hline 23 & $\begin{array}{c}\text { Melati } \\
\text { Ananda }\end{array}$ & Ahli & Kurang & Selalu & Kurang & $\begin{array}{l}\text { Tidak } \\
\text { Layak }\end{array}$ \\
\hline 24 & $\begin{array}{c}\text { Ryna } \\
\text { Nurhaina }\end{array}$ & Ahli & Ya & Jarang & Baik & Layak \\
\hline 25 & Ris Muhana & Kurang & $\mathrm{Ya}$ & Selalu & Baik & Layak \\
\hline 26 & $\begin{array}{c}\text { Melfa } \\
\text { Agustina } \\
\end{array}$ & Ahli & Kurang & Selalu & Kurang & $\begin{array}{r}\text { Tidak } \\
\text { Layak }\end{array}$ \\
\hline 27 & M. Agung & Ahli & Kurang & Selalu & Baik & Layak \\
\hline 28 & Asrori & Kurang & Ya & Jarang & Kurang & $\begin{array}{l}\text { Tidak } \\
\text { Layak }\end{array}$ \\
\hline 29 & $\begin{array}{c}\text { Rahmad } \\
\text { Bahri }\end{array}$ & Ahli & Ya & Selalu & Baik & Layak \\
\hline 30 & $\begin{array}{l}\text { Nazrianda } \\
\text { Syahpura }\end{array}$ & Kurang & Ya & Selalu & Kurang & $\begin{array}{r}\text { Tidak } \\
\text { Layak }\end{array}$ \\
\hline
\end{tabular}

Dimulai dari node akar di hitung dulu entropy untuk node akar (semua data) terhadap komposisi kelas.

$E($ semua $)=$

$$
\begin{aligned}
& -\left(\begin{array}{c}
(\mathrm{p}(\text { layak } / \text { semua }) * \log 2 \mathrm{p}(\text { layak} / \text { semua }))+ \\
(\mathrm{p}(\text { tidak layak/semua }) * \\
\log 2 \mathrm{p}(\text { tidak layak/semua }))
\end{array}\right) \\
& =-\left(\begin{array}{c}
((16 / 30) * \log 2(16 / 30))+ \\
((14 / 30) * \log 2(14 / 30))
\end{array}\right)
\end{aligned}
$$

$=0,9968$

Selanjutnya di hitung entropy setiap nilai fitur terhadap kelas. Untuk entropy nilai terhadap

'Keahlian' didapat:

$E\left(\right.$ semua $\left._{\text {Ahli }}\right)=$

$-\left(\begin{array}{c}(\mathrm{p}(\text { layak/ahli }) * \log 2 \mathrm{p}(\text { layak/ahli }))+ \\ (\mathrm{p}(\text { tidak layak/ahli }) * \log 2 \mathrm{p}(\text { tidak layak/ahli }))\end{array}\right)$

$=-\left(\begin{array}{c}((14 / 18) * \log 2(14 / 18))+ \\ ((4 / 18) * \log 2(4 / 18))\end{array}\right)$

$=0,7642$

$E\left(\right.$ semua $\left._{\text {Kurang }}\right)=$

$-\left(\begin{array}{c}(\mathrm{p} \text { (layak } / \text { kurang }) * \log 2 \mathrm{p}(\text { layak/kurang }))+ \\ (\mathrm{p}(\text { tidak layak/kurang }) * \\ \text { Log2 } \mathrm{p}(\text { tidak layak/kurang }))\end{array}\right)$

$=-\left(\begin{array}{c}((2 / 12) * \log 2(2 / 12))+ \\ ((10 / 12) * \log 2(10 / 12))\end{array}\right)$

$=0,65$

Untuk entropy nilai terhadap 'Kerapian' didapat:

$E\left(\right.$ semua $\left._{Y a}\right)=$

$-\left(\begin{array}{c}(\mathrm{p}(\text { layak/ya }) * \log 2 \mathrm{p}(\text { layak/ya }))+ \\ (\mathrm{p}(\text { tidak layak/ya }) * \log 2 \mathrm{p}(\text { tidak layak/ya }))\end{array}\right)$

$=-\left(\begin{array}{c}((12 / 18) * \log 2(12 / 18))+ \\ ((6 / 18) * \log 2(6 / 18))\end{array}\right)$ 
$=0,9183$

$E\left(\right.$ semua $\left._{\text {Kurang }}\right)=$

$-\left(\begin{array}{c}(\mathrm{p}(\text { layak } / \text { kurang }) * \log 2 \mathrm{p}(\text { layak } / \text { kurang }))+ \\ (\mathrm{p}(\text { tidak layak/kurang }) * \\ \log 2 \mathrm{p}(\text { tidak layak/kurang }))\end{array}\right)$

Page $\mid 50$

$=0,9183$

Untuk entropy nilai terhadap 'Kehadiran' didapat:

$E\left(\right.$ semua $\left._{\text {selalu }}\right)=$

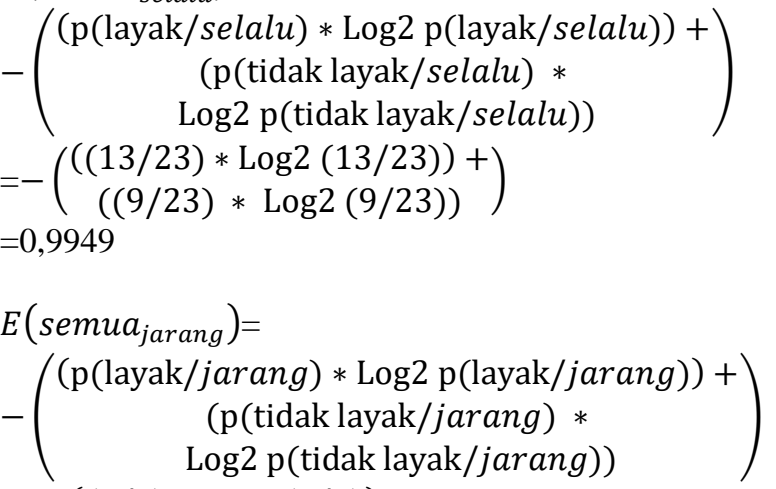

$=-\left(\begin{array}{c}((3 / 7) * \log 2(3 / 7))+ \\ ((4 / 7) * \log 2(4 / 7))\end{array}\right)$

$=0,9852$

Untuk entropy nilai terhadap 'Perilaku' didapat:

$E\left(\right.$ semua $\left._{\text {baik }}\right)=$

$$
\begin{aligned}
& -\left(\begin{array}{c}
(\mathrm{p}(\text { layak/baik }) * \log 2 \mathrm{p}(\text { layak } / \text { baik }))+ \\
(\mathrm{p}(\text { tidak layak/baik }) * \\
\log 2 \mathrm{p}(\text { tidak layak/baik }))
\end{array}\right) \\
& =-\left(\begin{array}{c}
((14 / 20) * \log 2(14 / 20))+ \\
((6 / 20) * \log 2(6 / 20))
\end{array}\right) \\
& =0,8813 \\
& E\left(\text { semua }_{\text {Kurang }}\right)= \\
& -\left(\begin{array}{c}
(\mathrm{p}(\text { layak } / \text { kurang }) * \log 2 \mathrm{p}(\text { layak } / \text { kurang }))+ \\
(\mathrm{p}(\text { tidak layak/kurang }) * \\
\log 2 \mathrm{p}(\text { tidak layak/kurang }))
\end{array}\right) \\
& =-\left(\begin{array}{c}
((2 / 10) * \log 2(2 / 10))+ \\
((8 / 10) * \log 2(8 / 10))
\end{array}\right) \\
& =0,7219
\end{aligned}
$$

Selanjutnya di hitung gain untuk setiap fitur.

G(semua, Keahlian)

$$
\begin{aligned}
& =E(\text { semua })-\sum_{i=1}^{n} p\left(v_{i} \mid \text { semua }\right) * \text { Esemua }_{\text {keahlian }} \\
& =E(\text { semua })-
\end{aligned}
$$$$
\left(\begin{array}{c}
\left(p(\text { ahli } \mid \text { semua }) * E\left(\text { semua }_{\text {ahli }}\right)\right)+ \\
\left.(\text { p(kurang } \mid \text { semua }) * E\left(\text { semua }_{\text {kurang }}\right)\right)
\end{array}\right)
$$$$
=0,9968-(((18 / 30 * 0,7642)+((12 / 30 * 0,65))
$$$$
=0,79828
$$

G(semua,Kerapian)

$=E($ semua $)-\sum_{i=1}^{n} p\left(v_{i} \mid\right.$ semua $) *$ Esemua $_{\text {kerapian }}$

$=E($ semua $)-$

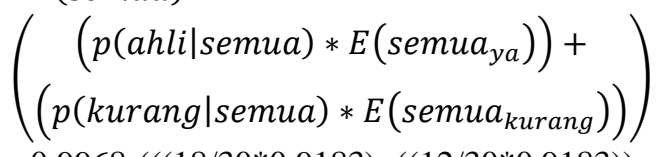

$=0,9968-(((18 / 30 * 0,9183)+((12 / 30 * 0,9183))$ $=0,81314$

G(semua, Kehadiran)

$=E($ semua $)-\sum_{i=1}^{n} p\left(v_{i} \mid\right.$ semua $)$

$=E($ semua $)-$

* Esemua $a_{k e h a d i r a n}$

$\left(\begin{array}{c}\left(p(\text { ahli } \mid \text { semua }) * E\left(\text { semua }_{\text {selalu }}\right)\right)+ \\ \left(p(\text { kurang } \mid \text { semua }) * E\left(\text { semua }_{\text {jarang }}\right)\right)\end{array}\right)$

$=0,9968-(((23 / 30 * 0,9949)+((7 / 30 * 0,9852))$ $=0,46392$

G(semua, Perilaku)

$=E($ semua $)-\sum_{i=1}^{n} p\left(v_{i} \mid\right.$ semua $) *$ Esemua $_{\text {perilaku }}$

\begin{tabular}{|c|c|c|c|c|c|c|c|}
\hline $\begin{array}{c}\text { Node } \\
1\end{array}$ & Atribut & $\begin{array}{l}\text { Nilai } \\
\text { Atribut }\end{array}$ & $\begin{array}{c}\text { Jumla } \\
\mathrm{h}\end{array}$ & $\begin{array}{c}\text { Laya } \\
\mathrm{k}\end{array}$ & $\begin{array}{c}\text { Tidak } \\
\text { Laya } \\
\text { k }\end{array}$ & $\begin{array}{l}\text { Entroph } \\
\text { y }\end{array}$ & \multirow[t]{2}{*}{ Gain } \\
\hline & & & 30 & 16 & 14 & 0,9968 & \\
\hline & \multirow[b]{2}{*}{ Keahlian } & Ahli & 18 & 14 & 4 & 0,7642 & \multirow{2}{*}{$\begin{array}{c}0,7982 \\
8\end{array}$} \\
\hline & & $\begin{array}{c}\text { Kuran } \\
\text { g }\end{array}$ & 12 & 2 & 10 & 0,65 & \\
\hline & \multirow[b]{2}{*}{ Kerapian } & $\mathrm{Ya}$ & 18 & 12 & 6 & 0,9183 & \multirow{2}{*}{$\begin{array}{c}0,8131 \\
4\end{array}$} \\
\hline & & $\begin{array}{c}\text { Kuran } \\
\mathrm{g}\end{array}$ & 12 & 4 & 8 & 0,9183 & \\
\hline & \multirow{2}{*}{ Kehadiran } & Selalu & 23 & 13 & 9 & 0,9949 & \multirow{2}{*}{$\begin{array}{c}0,4639 \\
2\end{array}$} \\
\hline & & Jarang & 7 & 3 & 4 & 0,9852 & \\
\hline & \multirow[b]{2}{*}{ Perilaku } & Baik & 20 & 14 & 6 & 0,8813 & \multirow[b]{2}{*}{0,6499} \\
\hline & & $\underset{\mathrm{g}}{\text { Kuran }}$ & 10 & 2 & 8 & 0,7219 & \\
\hline
\end{tabular}

$=E($ semua $)-$

$\left(\begin{array}{c}\left(p(\text { ahli } \mid \text { semua }) * E\left(\text { semua }_{\text {baik }}\right)\right)+ \\ \left(p\left({\text { kurang } \mid \text { semua }) * E\left(\text { semua }_{\text {kurang }}\right)}\right)\right)\end{array}\right)$

$=0,9968-(((20 / 30 * 0,8813)+((10 / 30 * 0,7219))$

$=0,6499$

Selengkapnya perhitungan entropy dan gain untuk node 1 akan di tampilkan pada tabel 3.

TABEL III

PERHITUNGAN ENTROPY DAN GAIN DI NODE 1

Hasil yang di dapat di tabel 3 menunjukkan bahwa gain tertinggi ada pada fitur kerapian. Sehingga fitur kerapian di jadikan node akar dan di jadikan daun. Untuk cabangnya, digunakan 2 nilai didalam node akar. Selanjutnya data akan terpecah menjadi 2 kelompok, yaitu "Ya" dan "Kurang". Seperti gambar dibawah ini :

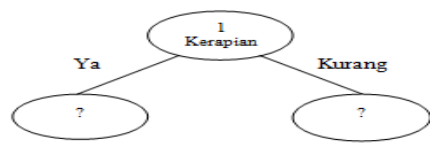

Gbr. 1 Node Akar Kerapian

Hasil permisahan pada node 1 fitur kerapian untuk cabang "Ya" akan di tampilkan pada tabel 4. 
TABEL IV

HASIL PEMISAHAN DATA PADA NODE 1 UNTUK CABANG "YA"

\begin{tabular}{|c|c|c|c|c|c|c|}
\hline No & Nama & Keahlian & Kerapian & Kehadiran & Perilaku & $\begin{array}{c}\text { Keteranga } \\
\text { n }\end{array}$ \\
\hline 2 & Masuhendra & Ahli & Ya & Selalu & Kurang & Layak \\
\hline 4 & Azizah & Ahli & Ya & Jarang & Baik & Layak \\
\hline 6 & $\begin{array}{c}\text { Citra } \\
\text { Pelangi }\end{array}$ & Ahli & Ya & Selalu & Baik & Layak \\
\hline 7 & $\begin{array}{c}\text { Aditya } \\
\text { Permana }\end{array}$ & Ahli & Ya & Selalu & Kurang & Layak \\
\hline 10 & $\begin{array}{c}\text { M.Permata } \\
\text { Sakti }\end{array}$ & Ahli & Ya & Selalu & Baik & Layak \\
\hline 11 & $\begin{array}{c}\text { Fuji } \\
\text { Amalubis }\end{array}$ & Kurang & Ya & Jarang & Kurang & $\begin{array}{c}\text { Tidak } \\
\text { Layak }\end{array}$ \\
\hline 13 & $\begin{array}{c}\text { Amalia } \\
\text { Safitri }\end{array}$ & Kurang & Ya & Selalu & Kurang & $\begin{array}{c}\text { Tidak } \\
\text { Layak }\end{array}$ \\
\hline 14 & $\begin{array}{c}\text { Ahmad } \\
\text { Alwani }\end{array}$ & Ahli & Ya & Jarang & Baik & Layak \\
\hline 16 & Abdul Khali & Ahli & Ya & Selalu & Baik & Layak \\
\hline 17 & $\begin{array}{c}\text { Husnani } \\
\text { Zuhra }\end{array}$ & Kurang & Ya & Selalu & Kurang & $\begin{array}{c}\text { Tidak } \\
\text { Layak }\end{array}$ \\
\hline 19 & $\begin{array}{c}\text { Dyana } \\
\text { Jafani }\end{array}$ & Ahli & Ya & Selalu & Baik & Layak \\
\hline 21 & $\begin{array}{c}\text { Murni } \\
\text { Rofika }\end{array}$ & Kurang & Ya & $\begin{array}{c}\text { Jarang } \\
\text { Hadir }\end{array}$ & Baik & $\begin{array}{c}\text { Tidak } \\
\text { Layak }\end{array}$ \\
\hline 22 & $\begin{array}{c}\text { Balqis } \\
\text { Amalia Sari }\end{array}$ & Kurang & Ya & Selalu & Baik & Layak \\
\hline 24 & $\begin{array}{c}\text { Ryna } \\
\text { Nurhaina }\end{array}$ & Ahli & Ya & Jarang & Baik & Layak \\
\hline 25 & Ris Muhana & Kurang & Ya & Selalu & Baik & Layak \\
\hline 28 & $\begin{array}{c}\text { Asrori } \\
\text { Bahri }\end{array}$ & Kurang & Ya & Jarang & Kurang & $\begin{array}{c}\text { Tidak } \\
\text { Layak }\end{array}$ \\
\hline 29 & $\begin{array}{c}\text { Rahmad } \\
\text { Syahpura }\end{array}$ & Kurang & Ya & Selalu & Kurang & $\begin{array}{c}\text { Tidak } \\
\text { Layak }\end{array}$ \\
\hline 30 & $\begin{array}{c}\text { Narianda } \\
\text { Layak }\end{array}$ & Selalu & Baik & Layak \\
\hline
\end{tabular}

Dalam perhitungan berikutnya. Fitur kerapian tidak dilibatkan. Berikut perhitungan node internal di cabang 'Ya'. Selanjutnya di hitung entropy setiap nilai fitur terhadap kelas. Hasil pehitungan gain dan entropy cabang 'Ya' dalam bentuk tabel.

TABEL V

PERHITUNGAN ENTROPY DAN GAIN PADA CABANG "YA" NODE 2

\begin{tabular}{|c|c|c|c|c|c|c|c|}
\hline $\begin{array}{c}\text { Nod } \\
\mathrm{e}\end{array}$ & Atribut & $\begin{array}{c}\text { Nilai } \\
\text { Atribut }\end{array}$ & $\begin{array}{c}\text { Jumla } \\
\mathrm{h}\end{array}$ & $\begin{array}{c}\text { Laya } \\
\mathrm{k}\end{array}$ & $\begin{array}{c}\text { Tidak } \\
\text { Laya } \\
\text { k } \\
\end{array}$ & $\begin{array}{l}\text { Entroph } \\
\text { y }\end{array}$ & \multirow[t]{2}{*}{ Gain } \\
\hline & & & 18 & 12 & 6 & 0,9183 & \\
\hline & \multirow[b]{2}{*}{ Keahlian } & Ahli & 10 & 10 & 0 & 0 & \multirow{2}{*}{$\begin{array}{c}1,2788 \\
8\end{array}$} \\
\hline & & $\begin{array}{c}\text { Kuran } \\
\mathrm{g}\end{array}$ & 8 & 2 & 6 & 0,8113 & \\
\hline & \multirow{2}{*}{$\begin{array}{c}\text { Kehadira } \\
\text { n }\end{array}$} & Selalu & 12 & 9 & 3 & 0,8113 & \multirow{2}{*}{$\begin{array}{c}0,7107 \\
7\end{array}$} \\
\hline & & Jarang & 6 & 3 & 3 & 1 & \\
\hline & \multirow[b]{2}{*}{ Perilaku } & Baik & 11 & 10 & 1 & 0,4395 & \multirow[b]{2}{*}{$\begin{array}{c}0,9853 \\
7\end{array}$} \\
\hline & & $\underset{\mathrm{g}}{\text { Kuran }}$ & 7 & 2 & 5 & 0,8631 & \\
\hline
\end{tabular}

Hasil yang di dapat di tabel 3.6 menunjukkan bahwa gain tertinggi ada pada fitur Keahlian. Sehingga fitur Keahlian di jadikan node akar. Untuk cabangnya, digunakan 2 nilai didalam node akar. Selanjutnya data akan terpecah menjadi 2 kelompok, yaitu "Ahli" dan "Kurang". Seperti gambar dibawah ini :

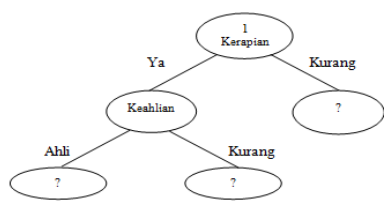

Gbr. 2 Node Akar Kerapian Cabang "Ya"

Selanjutnya hitung masing-masing entropy dan gain hingga ke node terakhir dan menghasilkan pohon keputusan dari permasalahan seleksi perangkingan pegawai kontrak menggunakan algoritma ID3.

Seperti pada gambar berikut ini :

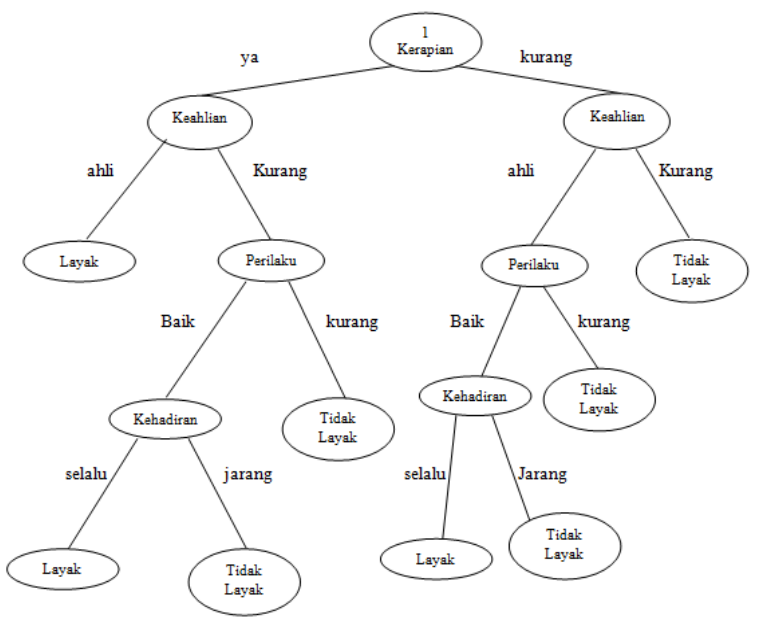

Gbr. 3 Hasil Pohon Keputusan

\section{KESIMPULAN DAN SARAN}

Ketika pohon keputusan seleksi perangkingan pegawai kontrak menggunakan algoritma ID3 sudah di dapat. Maka metode yang di gunakan di gabungkan dalam aplikasi visual basic 2010. Berikut hasil dari program dari visual basic 2010 menggunakan metode ID3.

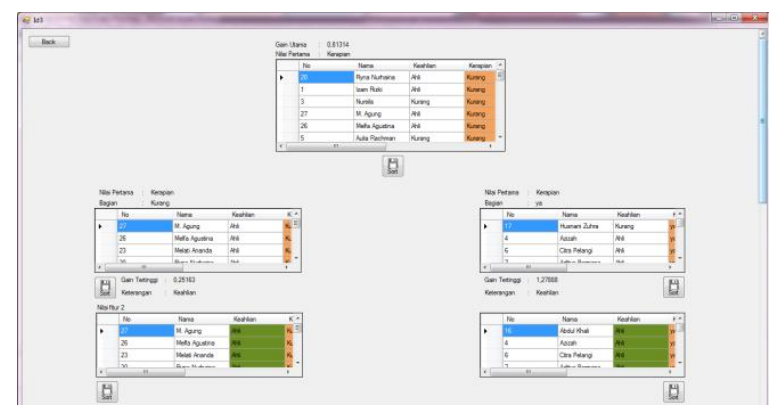

Gbr. 4 Hasil perhitungan data karyawan

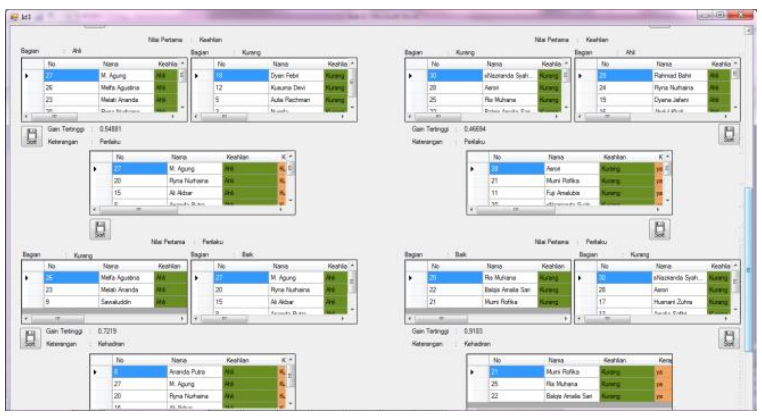

Gbr. 5 Hasil perhitungan data karyawan 


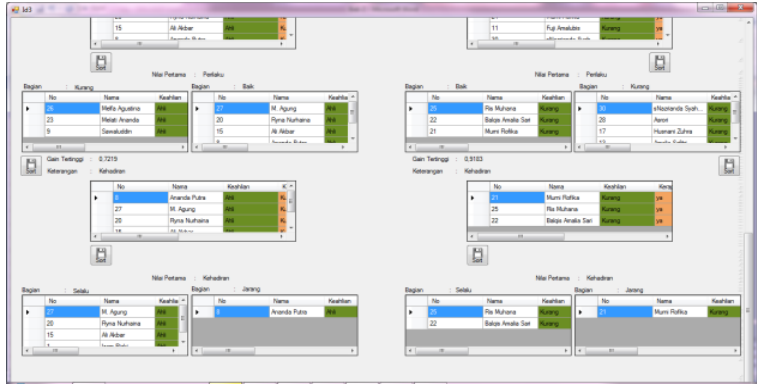

Gbr. 6 Hasil perhitungan data karyawan

Pohon yang di hasilkan dapat di nyatakan dalam bentuk IF THEN :

1) $I F$ kerapian = ya $A N D$ keahlian $=$ ahli Then keterangan $=$ layak

2) IF kerapian = ya $A N D$ keahlian = kurang $A N D$ perilaku $=$ kurang Then keterangan $=$ layak

3) IF kerapian = ya $A N D$ keahlian = kurang $A N D$ perilaku $=$ baik $A N D$ kehadiran $=$ jarang Then keterangan $=$ tidak layak

4) $\quad$ IF kerapian = ya $A N D$ keahlian = kurang $A N D$ perilaku $=$ baik $A N D$ kehadiran $=$ selalu Then keterangan = layak

5) $\quad$ IF kerapian $=$ kurang $A N D$ keahlian $=$ ahli $A N D$ perilaku $=$ kurang Then keterangan $=$ tidak layak

6) $I F$ kerapian $=$ kurang $A N D$ keahlian $=$ kurang Then keterangan $=$ tidak layak

7) $I F$ kerapian $=$ kurang $A N D$ keahlian $=$ ahli $A N D$ perilaku = baik $A N D$ kehadiran = selalu Then keterangan = layak

8) $I F$ kerapian $=$ kurang $A N D$ keahlian $=$ ahli $A N D$ perilaku $=$ baik $A N D$ kehadiran $=$ jarang Then keterangan $=$ tidak layak

Adapun saran dari penulis untuk program aplikasi penyeleksian pegawai kontrak apabila bila suatu saat aplikasi ini akan di jadikan suatu acuan maupun di kembangkan menjadi suatu penelitian adalah:

1) Fitur dan nilai fitur harus dapat otomatis tanpa harus mengatur ulang program dan tidak hanya mengikuti fitur maupun nilai fitur yang telah di tentukan.

2) Menambah sistem keamanan untuk mencegah terjadinya hacking atau yang lebih di kenal dengan kata pencurian data elektronik oleh orang yang tidak bertanggung jawab

3) Membuat sistem dapat di akses secara online sehingga membpermudah karyawan untuk melihat hasil penyeleksian dimana saja.

\section{DAFTAR PUSTAKA}

[1] S. Mallu and S. P. Keputusan, "Sistem pendukung keputusan penentuan karyawan kontrak menjadi karyawan tetap menggunakan metode topsis," vol. I, no. 2, pp. 36-42, 2015.

[2] S. Kasus, U. Dehasen, S. Haryati, A. Sudarsono, and E. Suryana, "IMPLEMENTASI DATA MINING UNTUK
MEMPREDIKSI MASA STUDI MAHASISWA MENGGUNAKAN ALGORITMA C4 . 5," vol. 11, no. 2, pp. 130-138, 2015.

[3] R. Aulia, "Pemanfaatan Website Sebagai Sarana Managing Data Dalam Suatu Organisasi (Studi Kasus: Pertemuan Ilmiah Nasional (Pin) Perhimpunan Dokter Spesialis Saraf Indonesia (Perdossi) 2013 Medan)," InfoTekJar (Jurnal Nas. Inform. dan Teknol. Jaringan), vol. 1, no. 1, pp. 1-6, 2016.

[4] C. M. Rumagit and C. Fibriani, "Penerapan Metode ID3 terhadap Perancangan Sistem Penentuan Penerima Bantuan Sosial Pemugaran RTLH Kota Salatiga," J. Nas. Teknol. dan Sist. Inf., vol. 2, no. 3, pp. 101-116, 2016.

[5] D. M. Agustina and Wijanarto, "Analisis Perbandingan Algoritma ID3 Dan C4.5 Untuk Klasifikasi Penerima Hibah Pemasangan Air Minum Pada PDAM Kabupaten Kendal,” $J$. Appl. Intell. Syst., vol. 1, no. 3, pp. 234-244, 2016.

[6] P. Meilina, "Penerapan Data Mining Dengan Metode Klasifikasi Menggunakan Decision Tree dan Regresi," $J$. Teknol., vol. 7, no. 1, pp. 11-20, 2015. 